\title{
Deep brain stimulation of the nucleus ventralis intermedius for Holmes (rubral) tremor and associated dystonia caused by upper brainstem lesions
}

\author{
Report of two cases
}

\author{
Guido Nikkhah, M.D., Ph.D., Thomas Prokop, M.D., Bernhard Hellwig, M.D., \\ Carl Hermann Lücking, M.D., and Christoph B. Ostertag, M.D.
}

Departments of Stereotactic and Functional Neurosurgery and Neurology, Neurocenter, Albert-Ludwigs-University, Freiburg, Germany

\begin{abstract}
$\checkmark$ Holmes tremor is caused by structural lesions in the perirubral area of the midbrain. Patients often present with associated symptoms such as dystonia and paresis, which are usually refractory to medical therapy. Here, the authors describe two patients in whom both tremor and associated dystonia improved markedly following unilateral stimulation of the thalamic nucleus ventralis intermedius.
\end{abstract}

\section{Key Words • Holmes tremor • dystonia • deep brain stimulation • nucleus ventralis intermedius}

$\mathrm{H}$ OLMES tremor is a rare movement disorder caused mainly by the disruption of the cerebellorubrothalamic projection system. Lesion sites associated with the tremor involve the red nucleus and neural fiber tracts originating in the cerebellum and the substantia nigra region. Holmes tremor is also known as "rubral" or "midbrain tremor" and was first described by Holmes in 1904. ${ }^{12}$ The underlying neuropathological origins vary considerably and include hemorrhage, ischemia, trauma, neoplasm, metabolic disorders, and infections. $7,12-14,17,18,20,27,29-32$

The tremor is clinically defined by the following criteria: it is present when the patient is at rest and pronounced by postural and intentional movements; and it has a slow frequency (usually less than $4.5 \mathrm{~Hz}$ ) and occurs with a time delay (usually weeks or years) following a lesion insult.7,9,10, ${ }^{12,32}$ Patients with Holmes tremor may also exhibit additional neurological symptoms such as dystonia, rigidity, and spastic paresis. . $2,18,20,29,32^{2}$

Current medical treatment strategies with levodopa, clonazepam, propranolol, and anticholinergic agents often fail to resolve the low-frequency tremor sufficiently and are largely unsuccessful against the occasionally associated dystonia and rigidity.,10,17,18 On the contrary, in individual cases, stereotactic thalamotomy, ${ }^{15}$ pallidotomy ${ }^{19}$ and thalamic DBS ${ }^{16,26}$ have been reported to alleviate Holmes tremor. Note that following DBS, clinical improvements can occur in associated dystonia and rigidity as well as tremor, as demonstrated in this study and not described previously.

Abbreviations used in this paper: $\mathrm{AVM}=$ arteriovenous malformation; $\mathrm{DBS}=$ deep brain stimulation; $\mathrm{MR}=$ magnetic resonance; Vim $=$ nucleus ventralis intermedius.
We report on two patients with unilateral upper brainstem lesions in whom contralateral DBS of the thalamic Vim effectively suppressed Holmes tremor and markedly alleviated dystonia and rigidity in both the upper and lower extremities.

\section{Case Reports}

Case 1

History and Examination. This 47-year-old right-handed woman without a remarkable medical history suddenly developed a disturbance of vigilance, double vision, dysarthria, hemiparesis, and mild hemiataxia on her left side. Magnetic resonance imaging revealed a right-sided infarct with a mean diameter of approximately $1 \mathrm{~cm}$ and situated in the midbrain region centered at the red nucleus. The lesion reached the lower border of the third ventricle and extended into the medial parts of the substantia nigra anteriorly and inferiorly (Fig. 1). Additionally, smaller ischemic subcortical lesions were observed bilaterally at the supratentorial level. The origin of these infarcts has remained obscure. A mild elevation in the patient's blood pressure and very low density lipoprotein levels were considered to be risk factors; all other studies performed during a stroke workup were normal.

Although the patient demonstrated some clinical improvement in subsequent months, her neurological status remained impaired. She showed a moderate left-sided spastic hemiparesis predominantly in the upper limb, a bradydiadochokinesia, a disabling and painful hemidystonia, and a mild Wernicke-Mann gait disturbance. Cognition and sensation were at normal levels. 

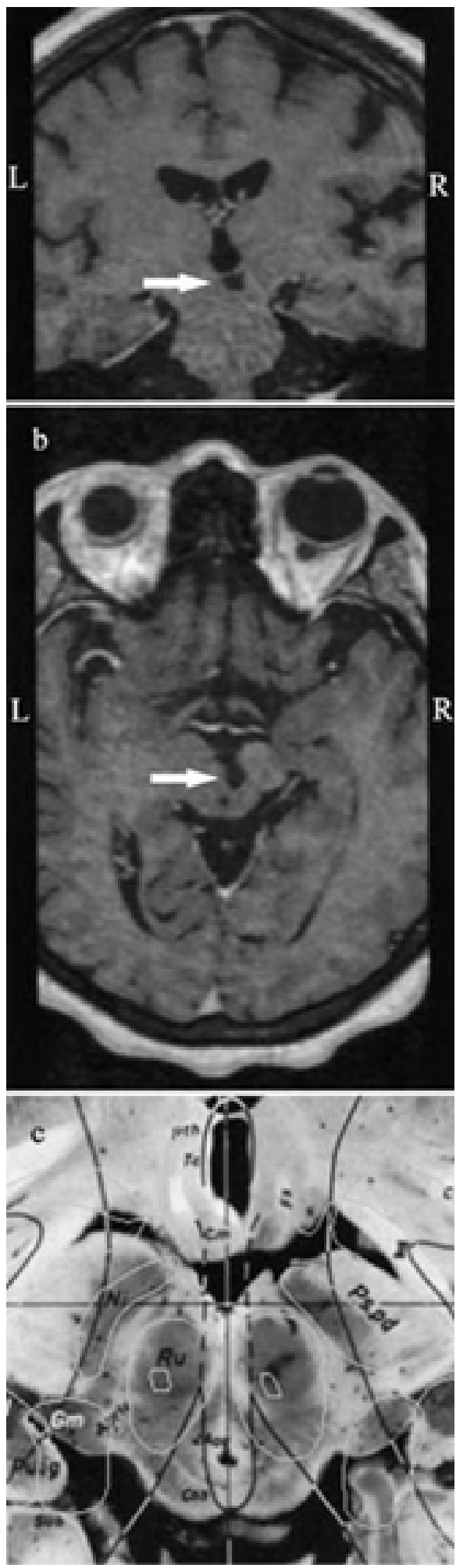

FIG. 1. Case 1. Coronal (a) and axial (b) $\mathrm{T}_{1}$-weighted Gd-enhanced MR images demonstrating the hypointense lesion (arrows) in the upper brainstem, including the red nucleus ( $\mathrm{Ru}$ in $\mathrm{c}$ ) and the substantia nigra area ( $\mathrm{Ni}$ in $\mathrm{c}$ ). The corresponding axial section from the Schaltenbrand stereotactic atlas is also shown (c). $\mathrm{L}=$ left; $\mathrm{R}=$ right. (Fig. 1c reprinted with permission from Schaltenbrand G, Wahren W: Atlas for Stereotaxy of the Human Brain. Georg Thieme Verlag, 1977.)
TABLE 1

Tremor analysis before and after thalamic Vim DBS in the unaffected (right) and affected (left) side in the patient in Case $1^{*}$

\begin{tabular}{|c|c|c|c|c|c|c|}
\hline \multirow[b]{2}{*}{ Tremor } & \multicolumn{3}{|c|}{ Rt Side } & \multicolumn{3}{|c|}{ Lt Side } \\
\hline & $\begin{array}{c}\text { Stimulation } \\
\text { Frequency } \\
(\mathrm{Hz})\end{array}$ & $\begin{array}{c}\text { Total } \\
\text { Power } \dagger\end{array}$ & $\begin{array}{c}\text { EMG } \\
\text { Synchro- } \\
\text { nization }\end{array}$ & $\begin{array}{l}\text { Stimulation } \\
\text { Frequency } \\
(\mathrm{Hz})\end{array}$ & $\begin{array}{c}\text { Total } \\
\text { Power } \dagger\end{array}$ & $\begin{array}{c}\text { EMG } \\
\text { Synchro- } \\
\text { nization }\end{array}$ \\
\hline \multicolumn{7}{|l|}{ preop } \\
\hline rest & 7.2 & 0.020 & no & 3.5 & 41.900 & yes \\
\hline action & 8.1 & 0.050 & no & 4.0 & 41.900 & yes \\
\hline \multicolumn{7}{|l|}{ postop } \\
\hline rest & 7.9 & 0.002 & no & 7.2 & 0.003 & no \\
\hline action & 7.3 & 0.003 & no & 7.1 & 0.410 & no \\
\hline
\end{tabular}

$* \mathrm{EMG}=$ electromyography.

$\dagger$ Total power refers to the area under the curve of the accelerometer spectrum and is measured in mgravities ${ }^{2}$.

Six months after the stroke, she developed a slowly progressive tremor in the left upper and lower limbs. The tremor occurred while at rest, was exacerbated in postures with action and intention, and was severely disabling. A semiquantitative analysis revealed a typical Holmes tremor at rest (frequency 3.5 seconds) and during action (frequency 4 seconds) on the left side and a physiological tremor on the right side (Table 1). Mild emotional enhancement was also observed. Sequential and combined pharmacotherapy as well as botulinum toxin injections in several muscles in the forearm induced only minor beneficial effects and some severe side effects; therefore, the tremor was regarded as refractory to medication, and the patient was referred for DBS.

Surgical Procedure. A modified Riechert-Mundinger stereotactic frame was fixed after administering local anesthesia, and the thalamic Vim target was calculated based on preoperative MR imaging and stereotactic computerized tomography scanning performed using image fusion software (STP4; Stryker-Leibinger, Freiburg, Germany). Intraoperative macrostimulation of the right Vim demonstrated an immediate reduction in the tremor in the left upper extremity and, to a lesser degree, in the left lower extremity. Therefore, a quadripolar DBS lead (model 3387; Medtronic, Inc., Minneapolis, MN) was implanted in the thalamic Vim on the right side, and the electrode tip was positioned to achieve maximal tremor suppression with only transitory facial paresthesia. We obtained postoperative MR images to confirm the placement of the quadripolar DBS lead in the target region of the right thalamic Vim.

Postoperative Course. Chronic high-frequency stimulation $(130 \mathrm{~Hz})$ with a pulse duration of $60 \mu \mathrm{sec}$ and an amplitude of $2.4 \mathrm{~V}$ abolished the patient's left side tremor almost completely (Table 1). Moreover, the rigidity in her left arm and the hemidystonia were significantly alleviated so that she was again able to hold a glass of water in her left hand and drink from it. Her postural instability improved considerably during walking, standing, and sitting, partially due to the absence of tremor in the left leg and body. During off stimulation the tremor reappeared within 1 minute. A side effect occurred with amplitudes greater than $3.5 \mathrm{~V}$ and consisted of a transient facial paresthesia on the left side. Clozapine could be withdrawn postoperatively without a re- 

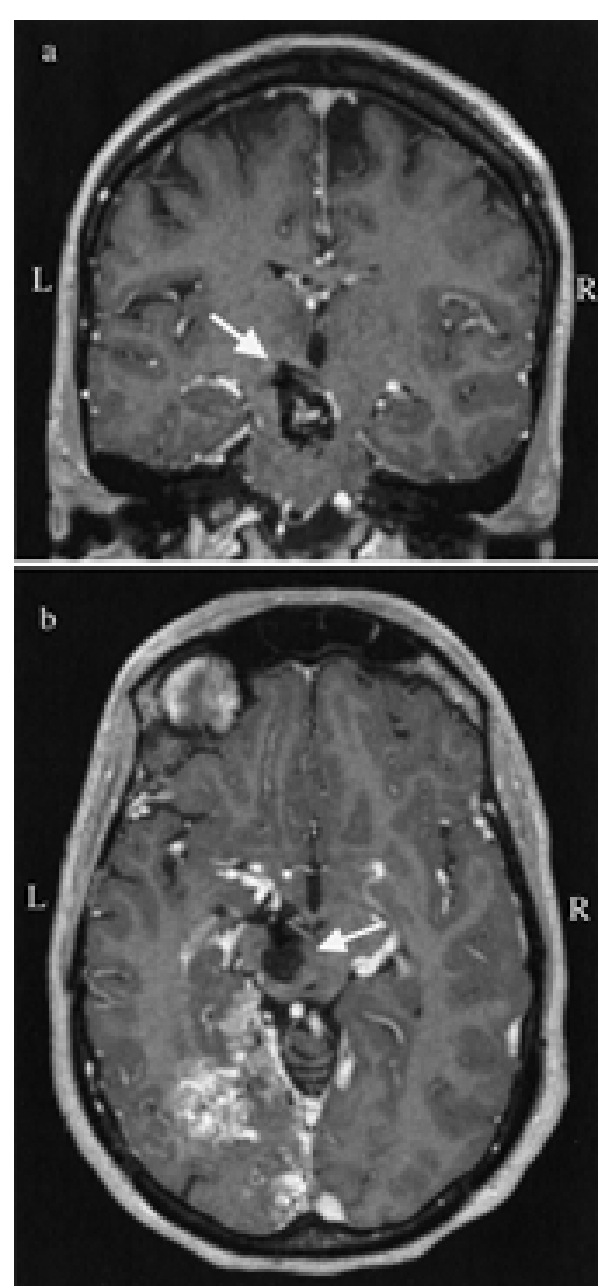

FIG. 2. Case 2. Coronal (a) and axial (b) $\mathrm{T}_{1}$-weighted Gd-enhanced MR images revealing the large AVM extending from the upper brainstem, including the lesioned area around the red nucleus and the substantia nigra (arrows) up to the left occipital lobe.

appearance of the tremor, and this clinical improvement has remained stable for 7 months postoperatively.

\section{Case 2}

History and Examination. This 32-year-old right-handed woman without a notable medical history suddenly became comatose and was admitted directly to the intensive care unit. An initial computerized tomography scan demonstrated a large hemorrhage covering the left midbrain and left thalamic region and extending to the left occipital lobe. Results of MR imaging (Fig. 2) and cerebral angiography studies revealed a large AVM that was fed by both the posterior and middle cerebral arteries and was associated with two small aneurysms at the $\mathrm{P}_{1}$ segment of the posterior cerebral artery.

Surgical Procedure and First Postoperative Course. First, both aneurysms were embolized with coils. Following clinical stabilization the patient presented with a severe right-sided hemiparesis, a complex disturbance of eye movements, and aphasic speech problems combined with dysarthria and hemianopia. Second, communicating hydrocephalus led to clinical deterioration and a permanent ce-
TABLE 2

Tremor analysis before and after thalamic Vim DBS in the unaffected (left) and affected (right) side in the patient in Case 2

\begin{tabular}{|c|c|c|c|c|c|c|}
\hline \multirow[b]{2}{*}{ Tremor } & \multicolumn{3}{|c|}{ Rt Side } & \multicolumn{3}{|c|}{ Lt Side } \\
\hline & $\begin{array}{c}\text { Stimulation } \\
\text { Frequency } \\
(\mathrm{Hz})\end{array}$ & $\begin{array}{c}\text { Total } \\
\text { Power }\end{array}$ & $\begin{array}{c}\text { EMG } \\
\text { Synchro- } \\
\text { nization }\end{array}$ & $\begin{array}{c}\text { Stimulation } \\
\text { Frequency } \\
(\mathrm{Hz})\end{array}$ & $\begin{array}{c}\text { Total } \\
\text { Power }\end{array}$ & $\begin{array}{l}\text { EMG } \\
\text { Synchro- } \\
\text { nization }\end{array}$ \\
\hline \multicolumn{7}{|l|}{ preop } \\
\hline rest & 3.2 & 2.700 & yes & 6.5 & 0.080 & no \\
\hline action* & - & - & - & 8.2 & 0.010 & no \\
\hline \multicolumn{7}{|l|}{ postop } \\
\hline rest & 8.2 & 0.005 & no & 7.3 & 0.006 & no \\
\hline action & 7.8 & 0.050 & no & 5.4 & 0.050 & no \\
\hline
\end{tabular}

* Because of the preoperative dystonia in the right arm, the patient was unable to stretch her arm to measure action tremor.

rebrospinal fluid shunt was implanted. In the following months she recovered slowly. The hemiparesis improved, but a dystonic component appeared in the right arm simultaneously. She was able to walk without help. Through a second-stage embolization procedure the size of the AVM was reduced, but total occlusion could not be achieved.

Three years later the patient's clinical status worsened and was again caused by reperfusion of an aneurysm and growth of the AVM. Additional embolizations were performed with subsequent partial clinical recovery. Following this episode she gradually developed a rest tremor, which was aggravated during posture and action on the right side, predominantly in her arm. The tremor had low frequency $(\sim 3 \mathrm{~Hz}$; Table 2$)$ and was first treated with clonazepam and propranolol, with only limited clinical success. Additional pharmacotherapy was largely ineffective; the tremor increased in severity so that she could not perform ordinary daily activities. At this point, she was referred for DBS.

Additional Treatments. On admission she presented with a severely disabling resting tremor in her right side (Table 2 ) and a dystonic posture in the hand and arm, which prevented her from spreading her fingers and lifting her arm. The tremor was markedly exacerbated during kinetic actions. Her speech was slurred and dysarthric, and her reflexes were increased on the right side but normal on the left. A Babinski sign was plantar on both sides. There was a slight hemianopia to the left. There was no sensory deficit. Her gait was slow with circumduction of the right leg, but heel-walk, toe-walk, and tandem-walk could be performed. Preoperative positron emission tomography studies revealed cerebellar hypometabolism and normal thalamic metabolism.

A quadripolar DBS lead (model 3387; Medtronic, Inc.) was implanted in the thalamic Vim on the left side, as described earlier. Electrostimulation (chronic high-frequency stimulation $130 \mathrm{~Hz}$, pulse duration $90 \mu \mathrm{sec}$, and amplitude $3.4 \mathrm{~V})$ significantly reduced $(\sim 80 \%)$ tremor activity on the right side. Moreover, the dystonic posture of the right arm improved, and the patient was able to spread her fingers much more quickly and to stretch out and elevate her arm up to $90^{\circ}$. When stimulation was turned off, tremor characteristics and dystonic symptoms immediately reappeared at preoperative baseline levels. No side effects were observed with the current stimulation parameters. The patient's speech improved as well. She has remained function- 
ally independent in all activities of daily living for at least 6 months postoperatively and has been able to return to work.

\section{Discussion}

Thalamic Vim stimulation has become a standard functional neurosurgical procedure for the treatment of tremor in patients with Parkinson disease and essential tremor ${ }^{2,4-6,8,}$ ${ }^{21,22}$ since its introduction by Benabid, et al., ${ }^{5}$ and Siegfried ${ }^{28}$ in 1987. Its effects on other forms of tremor have been reported less frequently, and there is very limited experience with patients suffering from Holmes tremor. ${ }^{8,16,23}$

Here, we report on two patients with medically intractable Holmes tremor caused by upper brainstem lesions and in whom unilateral thalamic Vim stimulation almost completely suppressed the tremor and markedly improved lesion-induced hemidystonia.

Both patients had suffered from lesions that involved the upper brainstem and thus interrupted the function of the cerebellorubrothalamic tracts. It is generally agreed that lesions of these pathways account for the tremor exacerbation during posture and kinetic action..$^{11,18,32}$ The resting tremor might have been caused by additional damage to the nigrostriatal pathway, ${ }^{25,32}$ which was also involved in the two patients we studied.

Medical treatment of Holmes tremor has thus far met with limited success in individual cases in which levodopa, anticholinergic agents, propanolol, clonazepam, and glutethimide were used ${ }^{14,17,25,29-32}$ and did not lead to satisfactory clinical benefits in the cases in the present study. In selected cases DBS and thermocoagulation may offer an alternative therapeutic strategy. ${ }^{18,15,16,21,23,27} \mathrm{Kim}$, et al., ${ }^{15}$ reported on a 26-year-old man in whom unilateral Vim thalamotomy almost completely abolished Holmes tremor that had been caused by a midbrain tumor. Two additional case reports of patients with a midbrain cavernous angioma ${ }^{16,23}$ document good to excellent clinical improvements in Holmes tremor following thalamic Vim stimulation. Both patients in the present study exhibited substantial clinical improvement in all tremor components (that is, during rest, posture, and intention movements) following unilateral thalamic Vim stimulation.

The mechanism of action in Vim stimulation leading to tremor suppression remains unresolved. Current hypotheses involve neuroaugmentive and neurosuppressive effects on neural network functioning, including the concept of jamming. ${ }^{3}$ Given that similar clinical responses occur after stereotactic lesioning and stimulation procedures, ${ }^{13,21,22}$ the interpretation of the responsible mechanism becomes even more complex. Nevertheless, stimulation techniques are considered to be safer and are reversible and therefore recommended in patients with substantial brain damage. ${ }^{3,22}$

Interestingly, clear improvement occurred in the tremor as well as the associated dystonia in both patients following unilateral Vim stimulation, which represents a result yet to be described in the literature. This recovery was gradual in nature and added significant clinical benefit in the patients; that is, it facilitated the rehabilitation process in both patients and enabled a return to professional activities in one patient. Phillips and Bhakta ${ }^{24}$ reported improved voluntary movements in the paretic arm and leg of a 48-year-old man who had suffered a stroke, following DBS of the periven- tricular gray matter in the third ventricle. ${ }^{24}$ They speculated that DBS close to the cerebral peduncle may have improved the function of motor pathways by the reinitiation of centrifugal information processing to the spinal cord previously damaged by the stroke. Similar mechanisms may have facilitated the clinical improvement in the hemidystonia in the cases in the present study.

\section{Conclusions}

In summary, thalamic Vim stimulation is an effective, safe, and reversible functional neurosurgical procedure for the treatment of patients with Holmes tremor and can alleviate associated dystonia and rigidity.

\section{References}

1. Andrew J, Fowler CJ, Harrison MJ: Tremor after head injury and its treatment by stereotaxic surgery. J Neurol Neurosurg Psychiatry 45:815-819, 1982

2. Atkinson JD, Collins DL, Bertrand G, et al: Optimal location of thalamotomy lesions for tremor associated with Parkinson disease: a probabilistic analysis based on postoperative magnetic resonance imaging and an integrated digital atlas. J Neurosurg 96:854-866, 2002

3. Benabid AL, Benazzouz A, Gao D, et al: Chronic electrical stimulation of the ventralis intermedius nucleus of the thalamus and of other nuclei as a treatment for Parkinson's disease. Tech Neurosurg 5:5-30, 1999

4. Benabid AL, Pollak P, Gao D, et al: Chronic electrical stimulation of the ventralis intermedius nucleus of the thalamus as a treatment of movement disorders. J Neurosurg 84:203-214, 1996

5. Benabid AL, Pollak P, Gervason C, et al: Long-term suppression of tremor by chronic stimulation of the ventral intermediate thalamic nucleus. Lancet 337:403-406, 1991

6. Benabid AL, Pollak P, Seigneuret E, et al: Chronic VIM thalamic stimulation in Parkinson's disease, essential tremor and extrapyramidal dyskinesias. Acta Neurochir Suppl 58:39-44, 1993

7. Berkovic SF, Bladin PF: Rubral tremor: clinical features and treatment of three cases. Clin Exp Neurol 20:119-128, 1984

8. Deuschl G, Bain P: Deep brain stimulation for tremor [correction of trauma]: patient selection and evaluation. Mov Disord 17 (Suppl 3):S102-S111, 2002

9. Deuschl G, Bain P, Brin M: Consensus statement of the Movement Disorder Society on Tremor. Ad Hoc Scientific Committee. Mov Disord 13 (Suppl 3):2-23, 1998

10. Deuschl G, Raethjen J, Lindemann M, et al: The pathophysiology of tremor. Muscle Nerve 24:716-735, 2001

11. Deuschl G, Wilms H, Krack P, et al: Function of the cerebellum in Parkinsonian rest tremor and Holmes' tremor. Ann Neurol 46: 126-128, 1999

12. Holmes G: On certain tremors in organic cerebral lesions. Brain 27:327-375, 1904

13. Hooper J, Simpson P, Whittle IR: Chronic posttraumatic movement disorder alleviated by insertion of meso-diencephalic deep brain stimulating electrode. Br J Neurosurg 15:435-438, 2001

14. Jacob PC, Pratap Chand R: Posttraumatic rubral tremor responsive to clonazepam. Mov Disord 13:977-978, 1998

15. Kim MC, Son BC, Miyagi Y, et al: Vim thalamotomy for Holmes' tremor secondary to midbrain tumor. J Neurol Neurosurg Psychiatry 73:453-455, 2002

16. Kudo M, Goto S, Nishikawa S, et al: Bilateral thalamic stimulation for Holmes' tremor caused by unilateral brainstem lesion. Mov Disord 16:170-174, 2001

17. Leung GK, Fan YW, Ho SL: Rubral tremor associated with cavernous angioma of the midbrain. Mov Disord 14:191-193, 1999 


\section{Deep brain stimulation for Holmes tremor and associated dystonia}

18. Miwa H, Hatori K, Kondo T, et al: Thalamic tremor: case reports and implications of the tremor-generating mechanism. Neurology 46:75-79, 1996

19. Miyagi Y, Shima F, Ishido K, et al: Posteroventral pallidotomy for midbrain tremor after a pontine hemorrhage. Case report. J Neurosurg 91:885-888, 1999

20. Mossuto-Agatiello L, Puccetti G, Castellano AE: "Rubral" tremor after thalamic haemorrhage. J Neurol 241:27-30, 1993

21. Niranjan A, Jawahar A, Kondziolka D, et al: A comparison of surgical approaches for the management of tremor: radiofrequency thalamotomy, gamma knife thalamotomy and thalamic stimulation. Stereotact Funct Neurosurg 72:178-184, 1999

22. Ostertag CB, Lücking CH, Mehdorn HM, et al: Stereotaktische behandlung der Bewegungsstorungen. Nervenarzt 68:477-484, 1997

23. Pahwa R, Lyons KE, Kempf L, et al: Thalamic stimulation for midbrain tremor after partial hemangioma resection. Mov Disord 17:404-407, 2002

24. Phillips NI, Bhakta BB: Affect of deep brain stimulation on limb paresis after stroke. Lancet 356:222-223, 2000

25. Remy P, de Recondo A, Defer G, et al: Peduncular 'rubral' tremor and dopaminergic denervation: a PET study. Neurology 45: 472-477, 1995

26. Romanelli P, Bronte-Stewart H, Courtney T, et al: Possible neces- sity for deep brain stimulation of both the ventralis intermedius and subthalamic nuclei to resolve Holmes tremor. Case report. J Neurosurg 99:566-571, 2003

27. Shepherd GM, Tauboll E, Bakke SJ, et al: Midbrain tremor and hypertrophic olivary degeneration after pontine hemorrhage. Mov Disord 12:432-437, 1997

28. Siegfried J: Therapeutic stereotactic procedures on the thalamus for motor movement disorders. Acta Neurochir 124:14-18, 1993

29. Tan H, Turanli G, Ay H, et al: Rubral tremor after thalamic infarction in childhood. Pediatr Neurol 25:409-412, 2001

30. Teive HA, Zanatta A, Germiniani FM, et al: Holmes' tremor and neuroparacoccidioidomycosis: a case report. Mov Disord 17: 1392-1394, 2002

31. Velez M, Cosentino C, Torres L: Levodopa-responsive rubral (Holmes') tremor. Mov Disord 17:741-742, 2002

32. Vidailhet M, Jedynak CP, Pollak P, et al: Pathology of symptomatic tremors. Mov Disord 13 (Suppl 3):49-54, 1998

Manuscript received October 20, 2003

Accepted in final form February 16, 2004

Address reprint requests to: Guido Nikkhah, M.D., Ph.D., Department of Stereotactic and Functional Neurosurgery, Neurocenter, Albert-Ludwigs University, Breisacher Strasse 64, D-79106 Freiburg, Germany. email: nikkhah@ukl.uni-freiburg.de. 